\title{
MOBP-specific cellular immune responses are weaker than MOG-specific cellular immune responses in patients with multiple sclerosis and healthy subjects
}

\author{
Samantha Jilek $\cdot$ Myriam Schluep • \\ Giuseppe Pantaleo $\cdot$ Renaud A. Du Pasquier
}

Received: 4 April 2012/ Accepted: 13 June 2012/Published online: 30 June 2012

(C) Springer-Verlag 2012

\begin{abstract}
Multiple sclerosis (MS) is an inflammatory and demyelinating disease of the central nervous system (CNS). Myelin oligodendrocyte glycoprotein (MOG) and myelin oligodendrocyte basic protein (MOBP) were both shown to be highly encephalitogenic in animal models of MS. In contrast, the association of MOG- and MOBPspecific humoral or cellular immune responses and MS in humans is far less established. In this study, we sought to analyse MOG- and MOBP-specific T-cell responses in a large cohort of patients with various stages of the disease. Patients with other neurological diseases and healthy subjects were enrolled to serve as control study subjects. We determined the proliferation and the secretion of IFN- $\gamma$ secretion in our cohort. We found that MOG-specific T-cell responses were higher and more frequent as compared to MOBP-specific ones. However, both MS patients and
\end{abstract}

S. Jilek · G. Pantaleo · R. A. Du Pasquier

Division of Immunology and Allergy, Department of Medicine,

Centre Hospitalier Universitaire Vaudois, Rue du Bugnon,

1011 Lausanne, Switzerland

e-mail: samantha.jilek-terrasse@chuv.ch

G. Pantaleo

e-mail: giuseppe.pantaleo@chuv.ch

M. Schluep · R. A. Du Pasquier

Division of Neurology, Department of Clinical Neurosciences,

Centre Hospitalier Universitaire Vaudois, Rue du Bugnon,

1011 Lausanne, Switzerland

e-mail: myriam.schluep@chuv.ch

R. A. Du Pasquier $(\square)$

Service de Neurologie, BH10, Centre Hospitalier

Universitaire Vaudois, 1011 Lausanne, Switzerland

e-mail: renaud.du-pasquier@chuv.ch control study subjects had similar myelin-specific T-cell responses at the periphery, thus calling for more precise studies at CNS level.

Keywords Myelin oligodendrocyte basic protein Myelin oligodendrocyte glycoprotein .

Cellular immune response $\cdot$ Multiple sclerosis

\section{Introduction}

Aetiology of multiple sclerosis (MS) is unknown, but dysregulated immunity plays a major role, as illustrated by the presence of cellular infiltrates composed of CD4+ and CD8+ T-cells, B cells and macrophages in MS plaques.

The myelin oligodendrocyte protein (MOG) is well known for its ability to generate encephalitogenic T-cell responses and induce experimental autoimmune encephalomyelitis (EAE) in mice [1]. In MS patients, MOG-specific cellular immune response takes place in the blood [2], and at the early stages, there is intrathecal synthesis of MOG-specific antibodies [3]. However, whereas an association of MOG antibodies and conversion to definite MS was shown [4], this was not confirmed by others [5].

The myelin-associated oligodendrocyte basic protein (MOBP), has been reported to cause EAE in susceptible mice [6]. Contrasting with MOG, MOBP has been poorly studied in MS patients, yet MOBP-specific T-cells are found in MS patients [7, 8].

Here, we sought to compare MOG- and MOBP-specific cellular immune responses in a large cohort of subjects including patients with MS, other neurological diseases (OND) and healthy subjects (HC). 


\section{Materials and methods}

\section{Subjects}

144 subjects were enrolled: 96 patients with MS and 48 control subjects. This study was accepted by our institution ethical commission. All subjects gave their written consent according to review board guidelines. Diagnosis of MS was made using the revised criteria of McDonald [9]. None of the subjects had received corticosteroids within 3 months before enrolment. Clinical data of the cohort are given in Table 1.

Peripheral blood mononuclear cells (PBMC)

PBMC were isolated as previously described [10] and either used directly or frozen.

\section{Peptides}

We used six pools of 15-mer MOG peptides and four pools of 15-mer MOBP peptides, overlapping by 10 amino acids (aa), and spanning the entire aa sequence of the proteins (SynPep Corporation, Dublin, CA). Each pool contained nine 15-mers and was used at a concentration of $10 \mu \mathrm{g} / \mathrm{ml}$.

Myelin-specific proliferating T-cells

Proliferation assays on freshly isolated PBMC were performed such as described previously [10]. Proliferation responses were calculated as stimulation index (SI), as determined by the mean ratio of antigen-stimulated counts per minute (cpm) over background cpm. Data are presented as cumulative SI, where results of all peptide pools were added for a given patient [10].

Myelin-specific IFN- $\gamma$-secreting T-cells

Enzyme-linked immunospot (ELISPOT) assays using frozen PBMC were performed such as previously described [10]. Responses were expressed as spot-forming cells (SFC) per $10^{6}$ PBMC. Background values corresponding to medium-stimulated PBMC were subtracted. Data are presented as cumulative SFC/10 6 cells where results of all peptide pools were added for a given patient [10].

Intracellular cytokine staining (ICS) assay

PBMC were cultured for 14 days in the presence of individual MOG peptide pools and IL-2 and an ICS assay was performed such as previously described [11]. Data were acquired on a LSRII flow cytometer (Becton-Dickinson, Franklin Lakes, NJ, USA) and analysed using FlowJo Software (Tree Star Inc., Ashland, OR, USA). Data are presented as cumulative percent of IFN- $\gamma$ secreting cells where results of all MOG peptide pools were added for a given patient.

\section{Statistics}

Statistical analysis was performed with GraphPad Prism software (GraphPad Software, San Diego, CA). Tests used included Kruskal-Wallis test for non-normally distributed variables, non-parametric Wilcoxon ranked test and twosided Fisher exact test. A $p<0.05$ was considered significant.

Table 1 Clinical data of the 144 patients enrolled

\begin{tabular}{|c|c|c|c|c|c|c|}
\hline & $\begin{array}{l}\text { Age at blood } \\
\text { draw in years }{ }^{\mathrm{a}}\end{array}$ & $\begin{array}{l}\text { Delay between disease onset } \\
\text { and study entrance in years }\end{array}$ & $\begin{array}{l}\text { Number } \\
\text { of relapses }{ }^{c}\end{array}$ & $\begin{array}{l}\text { EDSS } \\
\text { score }\end{array}$ & $\begin{array}{l}\text { Patients } \\
\text { in relapse }\end{array}$ & $\begin{array}{l}\text { Treated } \\
\text { patients }\end{array}$ \\
\hline \multicolumn{7}{|c|}{ Inflammatory MS $(n=67)$} \\
\hline CIS (30) & $39 \pm 20$ & $0.8 \pm 2.4$ & $1 \pm 0$ & $2 \pm 0.5$ & 5 & 1 \\
\hline RR-MS (37) & $37 \pm 11$ & $4.8 \pm 7.8$ & $3 \pm 3$ & $2.5 \pm 1$ & 18 & 8 \\
\hline \multicolumn{7}{|c|}{ Progressive MS $(n=29)$} \\
\hline SP-MS (14) & $61 \pm 14$ & $19.3 \pm 20.6$ & $3 \pm 4$ & $6 \pm 3$ & 0 & 0 \\
\hline PP-MS (15) & $54 \pm 11$ & $5.5 \pm 3.2$ & $0 \pm 0$ & $3 \pm 1.5$ & 1 & 0 \\
\hline \multicolumn{7}{|c|}{ Control subjects $(n=48)$} \\
\hline NIND (19) & $39 \pm 23$ & $0.3 \pm 1.9$ & $\mathrm{n} / \mathrm{a}$ & $\mathrm{n} / \mathrm{a}$ & $\mathrm{n} / \mathrm{a}$ & $\mathrm{n} / \mathrm{a}$ \\
\hline OIND (9) & $44 \pm 29$ & $0.2 \pm 0.3$ & $\mathrm{n} / \mathrm{a}$ & $\mathrm{n} / \mathrm{a}$ & $\mathrm{n} / \mathrm{a}$ & $\mathrm{n} / \mathrm{a}$ \\
\hline HC (20) & $33 \pm 14$ & $\mathrm{n} / \mathrm{a}$ & $\mathrm{n} / \mathrm{a}$ & $\mathrm{n} / \mathrm{a}$ & $\mathrm{n} / \mathrm{a}$ & $\mathrm{n} / \mathrm{a}$ \\
\hline
\end{tabular}




\section{A Cumulative myelin-specific T-cell responses (proliferation assays)}

MOBP
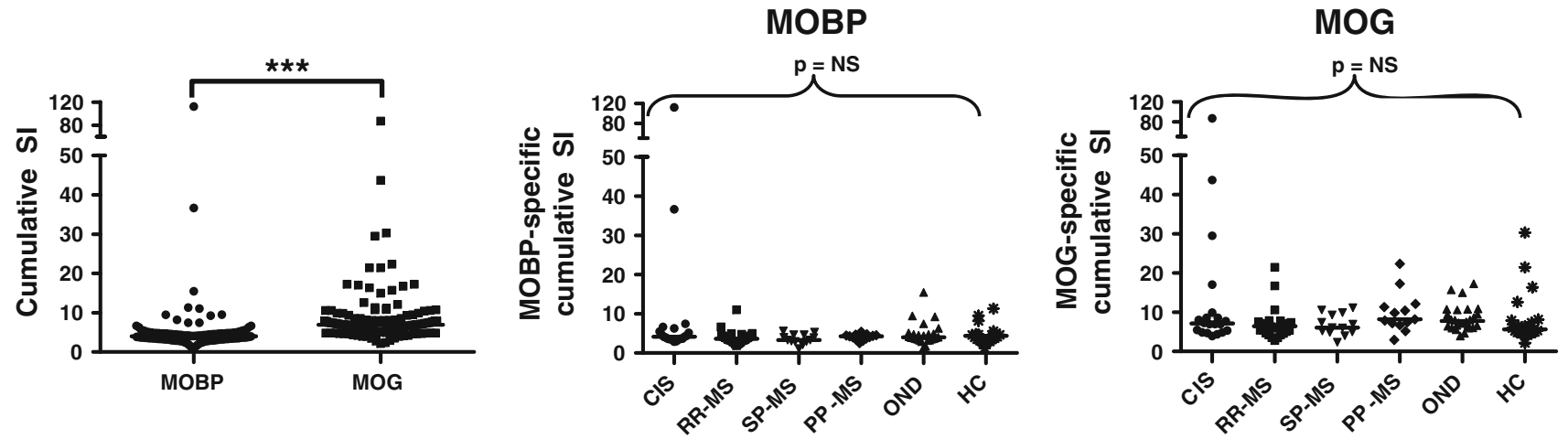

\section{B Cumulative myelin-specific IFN- $\gamma$ secretion (ELISPOT)}
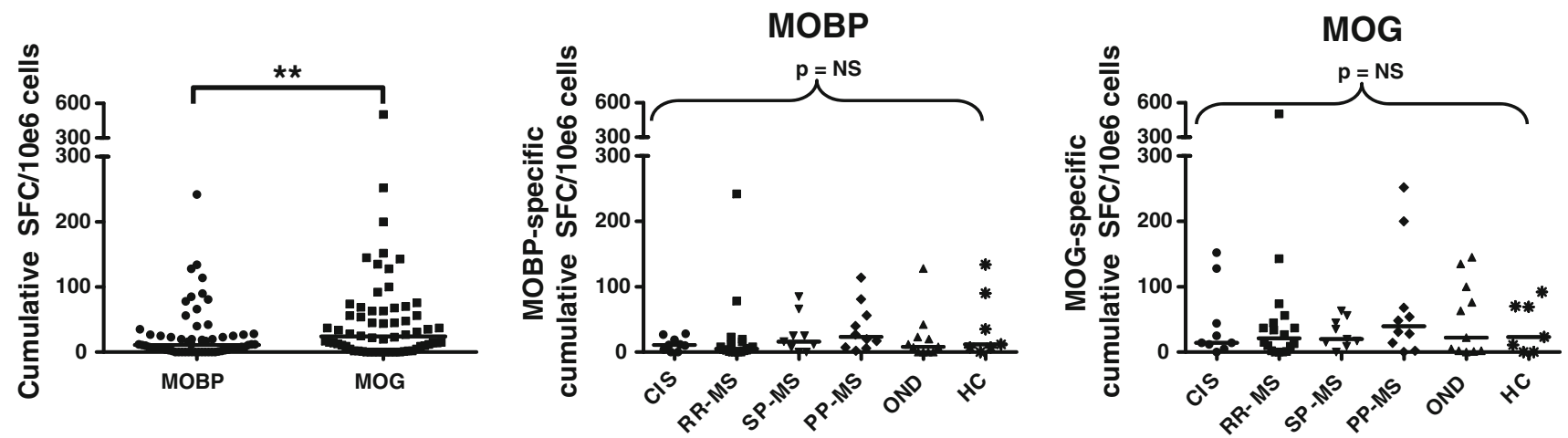

Fig. 1 MOBP- and MOG-specific cellular immune responses. a Cumulative T-cell responses against MOBP and MOG by proliferation assays, where all subject responses were plotted together (left panel). Middle panel describes the cellular immune response of the different groups against MOBP and right panel against MOG. b Cumulative T-cell responses against MOBP and MOG by ELISPOT assays (IFN- $\gamma$ secretion assay). Proliferation and ELISPOT data are presented as cumulative data where results of all peptide pools were added for a given patient. SI stimulation index, $S F C$ spot-forming cell, NS not significant; $* * p<0.01 ; * * * p<0.001$
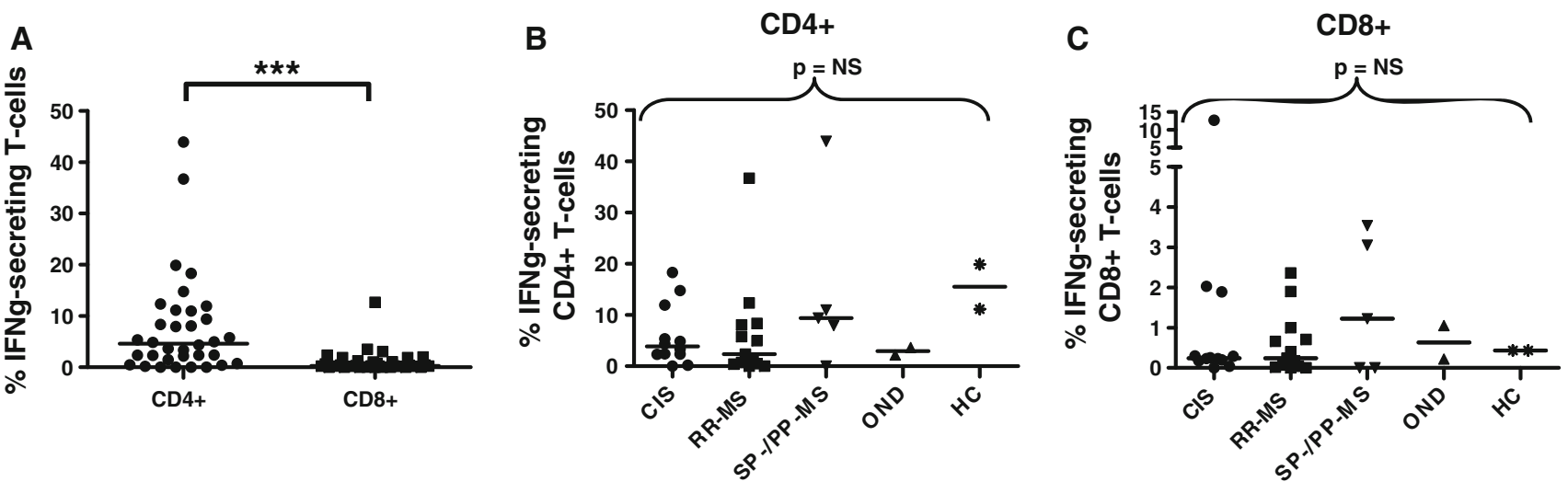

Fig. 2 MOG-specific CD4+ and CD8+ T-cells are present in all subjects after 14 days of stimulation. a All subjects were plotted on the same graph comparing CD4+ and CD8+ T-cells responses. Cumulative percentages of IFN- $\gamma$ secreting T-cells for the six MOG peptide pools are shown. b Subjects were divided into the different study subject categories and secretion of IFN- $\gamma$ by MOG-specific CD4+ T-cells presented as cumulative data. c Same as above for MOG-specific CD8+ T-cells. IFN- $\gamma$ secretion was assessed after 14 days of stimulation by ICS. NS not significant; ***p $<0.001$ 


\section{Results}

MOG- and MOBP-specific cellular immune responses were assessed by proliferation in 122 , by ELISPOT in 64 , and by ICS assays in 34 subjects.

By proliferation assays, we found that 44/122 (36\%) subjects responded to at least one pool of MOG peptides, whereas this rate was $17 / 122(14 \%)$ for MOBP pools $(p=0.0001)$. When the MOG- or MOBP-specific T-cell responses against the individual peptide pools were summed, the cumulative MOG-specific T-cell responses were significantly higher than the cumulative MOBP ones in the whole cohort $(p<0.0001$; Fig. 1a). However, for both myelin proteins, there was no difference in terms of prevalence or magnitude of responses among the different categories of study subjects (Fig. 1a).

Using ELISPOT assay, we found that only 11/64 study subjects $(17 \%)$ responded to at least one pool of MOG peptides and 5/64 (8\%) to MOBP peptides $(p>0.1$, Fig. 1b). The magnitude of the cumulative MOG-specific T-cell responses was significantly higher than the MOBP ones ( $p=0.0049$; Fig. 1b). And for a given myelin protein, there was no difference of prevalence or magnitudes of responses between the different categories of study subjects (Fig. 1b).

Since MOG was significantly more immunogenic than MOBP, we sought to determine which T-cell type was preferentially expanded after MOG peptide stimulation. We analysed the secretion of IFN- $\gamma$ in $30 \mathrm{MS}$ subjects and 4 control subjects by ICS in 14-day cultures. MOG-specific responses were present in all 34 subjects. The cumulative MOG-specific responses were higher in CD4+ T-cells than in $\mathrm{CD} 8+\mathrm{T}$-cells $(p<0.0001)$, without differences between the categories of study subjects (Fig. 2).

\section{Discussion}

We found that MOG was significantly more immunogenic than MOBP. However, there was no difference in terms of prevalence or magnitude of cellular immune response against one given protein between MS patients and control subjects. Overall, the myelin-specific T-cell responses were rather low. As for MOG, these findings are in line with a previous study which found no difference in the T-cell responses against $\mathrm{MOG}$, either $\mathrm{CD} 4+$ or $\mathrm{CD} 8+$, in $\mathrm{MS}$ patients as compared to HC [2]. MOBP was much less studied. Authors showed that MOBP-specific CD8+ T-cells were more activated in MS patients as compared to $\mathrm{HC}$ [8] and that MOBP-specific T-cell responses were positively correlated to clinical exacerbations [7]. However, others, like us, did not find differences in the MOBP-specific T-cell responses between MS patients and $\mathrm{HC}[6,12]$.
The fact that MOG-specific CD4+ T-cell response was not higher in CIS than other categories speaks against a significant role of these proteins shortly after disease onset. This observation stands in sharp contrast with EAE, where MOG-specific CD4+ T-cells are instrumental in triggering the disease [1]. Our findings may simply illustrate the fact that this aspect of EAE pathophysiology is not representative of MS. However, one cannot rule out that myelinspecific T-cell responses as assessed in the peripheral blood may have underestimate the response against similar antigen in the central nervous system (CNS) [11], since it is one of the main features of antigen-specific effector T-cells to migrate into sites of inflammation [13].

Therefore, studies examining the presence and phenotype of myelin-specific T-cells in the CNS are warranted to determine their putative role in the immunopathogenesis of MS.

Acknowledgments Work supported by grants from the SNF (FN 3200BO-104262 and PP00B-106716), the Swiss Society for Multiple Sclerosis and the Biaggi Foundation to RADP. We thank M. Canales and A. Monney for their technical assistance. We are grateful to Dr. J. Kleeberg and G. Le Goff for providing patient samples.

Conflict of interest The authors declare that they have no conflict of interest.

\section{References}

1. von Budingen HC, Tanuma N, Villoslada P, Ouallet JC, Hauser SL, Genain CP (2001) Immune responses against the myelin/ oligodendrocyte glycoprotein in experimental autoimmune demyelination. J Clin Immunol 21(3):155-170

2. Berthelot L, Laplaud DA, Pettre S, Ballet C, Michel L, Hillion S, Braudeau C, Connan F, Lefrere F, Wiertlewski S, Guillet JG, Brouard S, Choppin J, Soulillou JP (2008) Blood CD8+ T cell responses against myelin determinants in multiple sclerosis and healthy individuals. Eur J Immunol 38(7):1889-1899

3. Reindl M, Linington C, Brehm U, Egg R, Dilitz E, Deisenhammer F, Poewe W, Berger T (1999) Antibodies against the myelin oligodendrocyte glycoprotein and the myelin basic protein in multiple sclerosis and other neurological diseases: a comparative study. Brain 122(Pt 11):2047-2056

4. Berger T, Rubner P, Schautzer F, Egg R, Ulmer H, Mayringer I, Dilitz E, Deisenhammer F, Reindl M (2003) Antimyelin antibodies as a predictor of clinically definite multiple sclerosis after a first demyelinating event. N Engl J Med 349(2):139-145

5. Kuhle J, Pohl C, Mehling M, Edan G, Freedman MS, Hartung HP, Polman CH, Miller DH, Montalban X, Barkhof F, Bauer L, Dahms S, Lindberg R, Kappos L, Sandbrink R (2007) Lack of association between antimyelin antibodies and progression to multiple sclerosis. N Engl J Med 356(4):371-378

6. Holz A, Bielekova B, Martin R, Oldstone MB (2000) Myelinassociated oligodendrocytic basic protein: identification of an encephalitogenic epitope and association with multiple sclerosis. J Immunol 164(2):1103-1109

7. Arbour N, Holz A, Sipe JC, Naniche D, Romine JS, Zyroff J, Oldstone MB (2003) A new approach for evaluating antigenspecific $\mathrm{T}$ cell responses to myelin antigens during the course of multiple sclerosis. J Neuroimmunol 137(1-2):197-209 
8. Crawford MP, Yan SX, Ortega SB, Mehta RS, Hewitt RE, Price DA, Stastny P, Douek DC, Koup RA, Racke MK, Karandikar NJ (2004) High prevalence of autoreactive, neuroantigen-specific $\mathrm{CD} 8+\mathrm{T}$ cells in multiple sclerosis revealed by novel flow cytometric assay. Blood 103(11):4222-4231

9. McDonald WI, Compston A, Edan G, Goodkin D, Hartung HP, Lublin FD, McFarland HF, Paty DW, Polman CH, Reingold SC, Sandberg-Wollheim M, Sibley W, Thompson A, van den Noort S, Weinshenker BY, Wolinsky JS (2001) Recommended diagnostic criteria for multiple sclerosis: guidelines from the International Panel on the diagnosis of multiple sclerosis. Ann Neurol 50(1):121-127

10. Jilek S, Jaquiery E, Hirsch HH, Lysandropoulos A, Canales M, Guignard L, Schluep M, Pantaleo G, Du Pasquier RA (2010) Immune responses to JC virus in patients with multiple sclerosis treated with natalizumab: a cross-sectional and longitudinal study. Lancet Neurol 9(3):264-272

11. Jaquiery E, Jilek S, Schluep M, Meylan P, Lysandropoulos A, Pantaleo G, Du Pasquier RA (2010) Intrathecal immune responses to EBV in early MS. Eur J Immunol 40(3):878-887

12. Kerlero de Rosbo N, Kaye JF, Eisenstein M, Mendel I, Hoeftberger R, Lassmann H, Milo R, Ben-Nun A (2004) The myelinassociated oligodendrocytic basic protein region MOBP15-36 encompasses the immunodominant major encephalitogenic epitope(s) for SJL/J mice and predicted epitope(s) for multiple sclerosis-associated HLA-DRB1*1501. J Immunol 173(2):14261435

13. Woodland DL, Kohlmeier JE (2009) Migration, maintenance and recall of memory $\mathrm{T}$ cells in peripheral tissues. Nat Rev Immunol 9(3):153-161 